\title{
Clinico - Epidemiological Profile of Diabetic Ketoacidosis in Hospitalised Children at a Tertiary Health Care Centre
}

\section{Vijay Tukaram Mali, Saiprasad Onkareshwar Kavthekar, Sachin Verma, Anil Bapurao Kurane, Nivedita Balasaheb Patil and Suhas Panditrao Kulkarni}

Department of Paediatrics, D Y Patil Medical College, D Y Patil Education Society (Deemed to be University), Kolhapur, Maharashtra, India

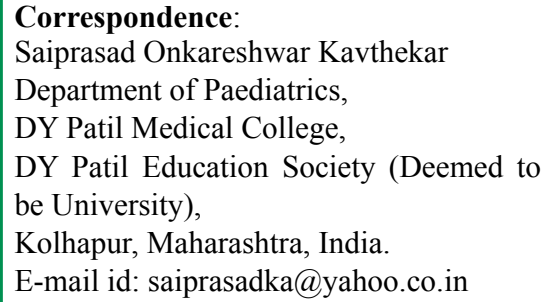

DOI: $10.3126 /$ jnps.v41i2.31136

Submitted on: $2020-09-10$

Accepted on: 2021-06-28

Acknowledgements: We would like to thank our Dean, Dr. R K Sharma for the whole hearted support extended to us throughout the conduct of the research.

Funding: Nil

Conflict of Interest: None declared

Permission from IRB: Yes

To cite this article: Mali VT, Kavthekar SO, Verma S, Kurane AB, Patil NB, Kulkarni SP. Clinico-Epidemiological Profile of Diabetic Ketoacidosis in Hospitalised Children at a Tertiary Health Care Centre. J Nepal Paediatr Soc. 2021;41(2):147-53.

\section{ABSTRACT}

Introduction: Diabetic Ketoacidosis (DKA) presents with spectrum of clinical manifestations and awareness regarding this amongst physicians is crucial. The study aimed to chronicle the clinical profile of DKA in type 1 diabetes mellitus (T1DM) children.

Methods: The study was conducted at a tertiary care hospital including patients with signs and symptoms of DKA with either debut or established T1DM $(n=38)$. Detailed clinical history, examination and laboratory investigations were carried out. Differences in frequency distribution concerning demographics and clinical data were analysed in R-studio software (v.1.2.5001).

Results: Kussmaul breathing (49.97\%) was the commonest presentation. Infection $(39.46 \%)$ and poor compliance due to inadvertent omission of insulin therapy $(50 \%)$ were the commonest precipitating factors. Mild, moderate and severe dehydration was present in $44.74 \%, 39.47 \%$ and $15.79 \%$ respectively. Forty-five percent patients had moderate while $34.21 \%$ and $21.05 \%$ had mild and severe DKA respectively. Seventy-five percent and $52 \%$ patients were below $3^{\text {rd }}$ percentile for height and weight respectively. High number of patients had past history of viral infections, were diagnosed in winter, belonged to $2^{\text {nd }}$ or $3^{\text {rd }}$ birth order and from lower middle class. Patients with poor compliance to insulin belonged to lower middle (40\%), upper lower (53.33\%) and lower class (6.67\%).

Conclusions: DKA can be diagnosed early by identifying dehydration, Kussmaul breathing, polyuria and altered sensorium. Infection and poor compliance due to omission of insulin therapy were the commonest and preventable precipitating factor for DKA. Poor compliance to insulin can be attributed to lower socioeconomic class. Awareness among physicians concerning clinical profile of DKA is crucial.

Key words: Clinical profile; Diabetic Ketoacidosis; Precipitating factors; Socio-economic class; Type 1 Diabetes Mellitus 


\section{INTRODUCTION}

Type 1 diabetes mellitus (T1DM) is among the common auto-immune, endocrinal disorder in children caused due to destruction of $\beta$ cell. ${ }^{1}$ T1DM mostly presents as diabetic ketoacidosis (DKA) and is the commonest paediatric endocrine emergency. ${ }^{2}$ The prevalence of DKA at diagnosis of T1DM and in established T1DM varies widely and ranges from $13-80 \%$ and from six to $28 \%$ respectively in different countries. ${ }^{3}$ The clinical signs of DKA includes dehydration, tachycardia, tachypnoea, deep sighing respiration, breath smell of acetone, nausea and / or vomiting, abdominal pain, blurry vision, confusion, drowsiness, progressive decrease in level of consciousness and eventually, loss of consciousness (coma) etc. ${ }^{4}$ The primary risk factors for DKA is especially more in poorer countries due to delayed diagnosis, lower prevalence, poor compliance, limited access to medical services etc. ${ }^{4}$

DKA mimics infections and other acute medical conditions due to its varied clinical presentation. Therefore, it is associated with high mortality if misdiagnosed and mismanaged. ${ }^{5}$ Early diagnosis and management of DKA prevents short-term and long-term complications. Therefore, awareness on the part of the physician accompanied by accessibility and availability of primary health-care facilities widely contributes to better management. ${ }^{6}$ Additionally, there is overwhelming evidence that lack of awareness regarding symptoms, signs, and clinical profile of DKA in T1DM among individuals and physicians have resulted in increased mortality in developing countries. ${ }^{7}$

Studies that deal exclusively with clinical profile of DKA in children of the Indian subcontinent are rather sparse. This study aimed to evaluate the clinico-epidemiological profile of DKA at presentation in hospitalised children with T1DM at a tertiary health care centre in Western part of India.

\section{METHODS}

The prospective study was conducted at the Department of Paediatrics at a tertiary health care centre in Kolhapur, Maharashtra, Western India between January 2018 to December 2019. The study was approved by Institutional Ethics committee. Informed and written consent from parents / guardian was obtained. Sample size was calculated using standard formula $\left[n=Z^{2} P(1-P) / d^{2}\right.$ to estimate proportion considering level of confidence $(Z)=1.96$, expected prevalence or proportion $(\mathrm{P})=0.02$ and level of precision $(\mathrm{d})=$ 0.05 . Thirty-eight children below 18 years of age with either debut or established T1DM admitted in the PICU with signs and symptoms and laboratory parameters of DKA were included. The demographic data (age, sex, height, weight), clinical data (presenting complaints, duration of symptoms, associated symptoms and precipitating factors for DKA episodes) and other clinical history including history of past infections, season at which they were first diagnosed, family diabetic history, birth weight in kilograms (High > 2.7, Normal 2.5 2.7 , Low $<2.5$ ), birth order, diet history specifically feeding in the first six months were collected. Details of Socioeconomic status as per modified Kuppuswamy's scale were also collected.

${ }^{8}$ Degree of dehydration was assessed clinically as mild $(5 \%)$, moderate $(5-10 \%)$ and severe $(>10 \%)$. ${ }^{4}$ Growth parameters like height and weight of the children were assessed according to World Health Organisation 2006 and Indian Academy of Paediatrics 2015 combined height and weight growth charts for 0 to 18 years. ${ }^{9,10}$ In children with established T1DM, additional data regarding duration of diabetes and compliance for insulin therapy either good or poor were collected. The poor compliance for insulin therapy was categorised as omission of insulin (either inadvertently or deliberately due to psychosocial issue) or due to limited access to medical services.

Along with detailed clinical history and examination, laboratory investigations including total blood count, serum and urine sugar, venous blood gases (VBG), serum electrolytes, urine ketone bodies, urine culture and blood cultures were carried out to confirm and manage DKA. Radiological investigations like $\mathrm{x}$-ray chest and USG abdomen were done wherever required. DKA was defined as the presence of blood sugar $>200$ $\mathrm{mg} / \mathrm{dl}$ with a venous $\mathrm{pH}<7.3$ and or bicarbonate $<$ $15 \mathrm{mmol} / \mathrm{L}$ with associated glycosuria, ketonuria and ketonemia. ${ }^{5}$ The severity of DKA was categorised by the degree of acidosis on VBG (Mild: $\mathrm{pH}<7.3$ or serum bicarbonate $<15 \mathrm{mmol} /$ L; moderate: $\mathrm{pH}<7.2$, serum bicarbonate $<10$ 
$\mathrm{mmol} / \mathrm{L}$ and Severe: $\mathrm{pH}<7.1$, serum bicarbonate $<$ $5 \mathrm{mmol} / \mathrm{L}){ }^{4}$ All the patients diagnosed with DKA were managed as per International Society for Paediatric and Adolescent Diabetes (ISPAD) clinical practice consensus guidelines 2018 protocol. ${ }^{4}$ During treatment other possible complications like cerebral oedema, electrolyte abnormalities and acute renal failure, to name few were also evaluated and managed accordingly. After successful management of acute DKA episode, at the time of discharge all patients were advised to undergo treatment with basal bolus Insulin therapy with appropriate counselling and regular follow-up.

The data collected was organised in MS Excel (2016). Frequency distribution concerning demographics, history and clinical data were studied. Data is represented as frequency, percentage and mean \pm SD where relevant. Differences in proportion of population based on various factors were analysed in $\mathrm{R}$ studio software (v.1.2.5001).

\section{RESULTS}

Of the total 38 patients, $21.1 \%(n=8)$ were debut and $78.9 \%(n=30)$ were established DKA. The age of the patients ranged between five months to 12 years with the mean age of $7.4 \pm 3.7$ years. High number of patients $(52.6 \% ; \mathrm{n}=20)$ were diagnosed within first four years of life followed by $34.2 \%$ (n $=13)$ and $13.2 \%(n=5)$ at the age of $4-8$ years and $8-12$ years respectively. The gender distribution was balanced with $47 \%(n=18)$ males and $53 \%(\mathrm{n}=20)$ females.

Clinical data of the patients is represented in Table 1. Significantly high number of patients $(49.97 \%$; $n$ $=19$ ) had Kussmaul breathing during admission. Dehydration was present in all patients with DKA. Infection was observed in $39.46 \%(n=15)$ and was the commonest precipitating factor, of which UTI was observed in $13.16 \%(n=5)$ patients. Of the five UTI patients, two patients showed the presence of Klebsiella species and three showed presence of Escherichia coli on urine culture. In established diabetes patients $(\mathrm{n}=30)$, poor compliance with insulin therapy was observed in $50 \%(\mathrm{n}=15)$ patients with DKA. However, inadvertent omission of insulin was the chief reason of poor compliance among all the patients.
Table 1. Clinical data of DKA patients

\begin{tabular}{|c|c|}
\hline Clinical data & Frequency (\%) \\
\hline \multicolumn{2}{|l|}{$\begin{array}{l}\text { Presenting complaints during } \\
\text { admission }\end{array}$} \\
\hline Fast breathing (Kussmaul) & $19(49.97 \%)$ \\
\hline Vomiting & $16(42.08 \%)$ \\
\hline Fever & $14(36.82 \%)$ \\
\hline Polyuria & $10(26.30 \%)$ \\
\hline Altered sensorium & $08(21.06 \%)$ \\
\hline Weight loss & $06(15.78 \%)$ \\
\hline Abdominal pain & $05(13.15 \%)$ \\
\hline Burning micturition & $03(07.89 \%)$ \\
\hline Polyphagia and polydipsia & $02(05.26 \%)$ \\
\hline \multicolumn{2}{|l|}{ Duration of symptoms } \\
\hline$<2$ days & $09(23.69 \%)$ \\
\hline 2 - 5 days & $20(52.63 \%)$ \\
\hline $5-10$ days & $07(18.42 \%)$ \\
\hline$>10$ days & $02(5.26 \%)$ \\
\hline \multicolumn{2}{|l|}{ Degree of dehydration } \\
\hline Mild (5\%) & $17(44.74 \%)$ \\
\hline Moderate $(5-10 \%)$ & $15(39.47 \%)$ \\
\hline Severe $(>10 \%)$ & $06(15.79 \%)$ \\
\hline \multicolumn{2}{|l|}{ Precipitating factors } \\
\hline \multicolumn{2}{|l|}{ Infections } \\
\hline UTI & $05(13.16 \%)$ \\
\hline Acute pharyngotonsillitis & $04(10.52 \%)$ \\
\hline Septicaemias & $02(05.26 \%)$ \\
\hline Severe balanoposthitis & $01(02.63 \%)$ \\
\hline Dental caries with abscess & $01(02.63 \%)$ \\
\hline Pneumonia & $01(02.63 \%)$ \\
\hline Neck abscess & $01(02.63 \%)$ \\
\hline \multicolumn{2}{|l|}{$\begin{array}{l}\text { Poor compliance with insulin } \\
\text { therapy among patients with } \\
\text { established T1DM }(\mathbf{n}=\mathbf{3 0}) \\
\text { (A) Insulin Omission }\end{array}$} \\
\hline $\begin{array}{l}\text { (A) Insulin Omission } \\
\text { 1. Inadvertently }\end{array}$ & $15(50.00 \%)$ \\
\hline $\begin{array}{l}\text { 2. Deliberately (Psychosocial } \\
\text { issue) }\end{array}$ & $00(0.00 \%)$ \\
\hline $\begin{array}{l}\text { (B) Limited access to medical } \\
\text { services }\end{array}$ & $00(0.00 \%)$ \\
\hline \multicolumn{2}{|l|}{ Inflammations } \\
\hline Transverse Myelitis & $01(02.63 \%)$ \\
\hline \multicolumn{2}{|l|}{ Non-compliant Diet } \\
\hline $\begin{array}{l}\text { High carbohydrates / sugar } \\
\text { and junk food diet }\end{array}$ & $01(02.63 \%)$ \\
\hline Nil & $06(15.78 \%)$ \\
\hline
\end{tabular}

Of the total 38 patients, 14 (36.84\%) patients were infected with virus in the recent past. Significantly high number of patients were first diagnosed during winter $(76.3 \% ; \mathrm{n}=29)$ and did not had any family history of diabetes $(71.05 \% ; \mathrm{n}=27)$. Also, significantly high number of patients had normal birth weight $(76.31 \% ; \mathrm{n}=29)$ and belonged to $2^{\text {nd }}$ $(36.84 \% ; \mathrm{n}=14)$ or $3^{\text {rd }}(36.84 \% ; \mathrm{n}=14)$ birth order respectively. Although statistically insignificant, high number of patients were fed 
Table 2. Epidemiological data of DKA patients

\begin{tabular}{|c|c|}
\hline Variables & Frequency $(\%)$ \\
\hline \multicolumn{2}{|l|}{ Past infections } \\
\hline Viral infections & $14(36.84 \%)$ \\
\hline Pneumonia & $02(05.26 \%)$ \\
\hline None & $22(57.90 \%)$ \\
\hline \multicolumn{2}{|l|}{ Season at first diagnosis } \\
\hline Winter & $30(78.94 \%)$ \\
\hline Rainy & $04(10.53 \%)$ \\
\hline Summer & $04(10.53 \%)$ \\
\hline \multicolumn{2}{|l|}{ Family history } \\
\hline Paternal Diabetes & $10(26.32 \%)$ \\
\hline Maternal Diabetes & $01(02.63 \%)$ \\
\hline None & $27(71.05 \%)$ \\
\hline \multicolumn{2}{|l|}{ Birth weight in $\mathrm{Kg}$} \\
\hline High $(>2.7)$ & $00(0.00 \%)$ \\
\hline Normal $(2.5-2.7)$ & $29(76.31 \%)$ \\
\hline Low $(<2.5)$ & $09(23.68 \%)$ \\
\hline \multicolumn{2}{|l|}{ Birth order } \\
\hline 01 & $05(13.15 \%)$ \\
\hline 02 & $14(36.84 \%)$ \\
\hline 03 & $14(36.84 \%)$ \\
\hline 04 & $03(07.89 \%)$ \\
\hline 05 & $01(02.63 \%)$ \\
\hline 06 & $01(02.63 \%)$ \\
\hline \multicolumn{2}{|l|}{ Feeding in the first six months } \\
\hline Exclusive Breast feeding & $22(57.8 \%)$ \\
\hline Other Milk & $16(42.10 \%)$ \\
\hline Cow & $6(15.79 \%)$ \\
\hline Goat & $513.16 \%)$ \\
\hline Mix & $5(13.16 \%)$ \\
\hline \multicolumn{2}{|l|}{ Socio-economic status } \\
\hline Upper class & $00(0.00 \%)$ \\
\hline Upper middle class & $03(07.89 \%)$ \\
\hline Lower middle class & $17(44.7 \%)$ \\
\hline Upper lower class & $14(36.84 \%)$ \\
\hline Lower class & $04(10.52 \%)$ \\
\hline
\end{tabular}

exclusively by breast milk $(57.8 \% ; \mathrm{n}=22)$. Number of patients belonging to lower middle class were significantly high $(44.7 \%, \mathrm{n}=17)$ (Table 2$)$.

Among 15 patients with poor compliance, $40 \%$ (n $=6$ ) patients belonged to lower middle class family, $53.33 \%(\mathrm{n}=8)$ and $6.67 \%(\mathrm{n}=1)$ patients belonged to upper lower class and lower class family respectively. Assessment of growth concerning height and weight revealed that $75 \%$ (n $=25)$ and $52 \%(\mathrm{n}=20)$ children were below $3^{\text {rd }}$ percentile for height and weight respectively.

Among the patients with established T1DM $(\mathrm{n}=$ $30), 43.33 \%(\mathrm{n}=13)$ patients had diabetic history
Table 3. Laboratory data of DKA patients $(n=38)$

\begin{tabular}{|cr|}
\hline Parameters & Frequency (\%) \\
\hline Random Blood Sugar (mg/dl) & \\
$251-300$ & $08(21.06 \%)$ \\
$301-350$ & $08(21.06 \%)$ \\
$351-400$ & $04(10.52 \%)$ \\
$401-450$ & $10(26.30 \%)$ \\
$451-500$ & $08(21.06 \%)$ \\
\hline Urine sugar level & \\
1 (Mild) & $00(0.00 \%)$ \\
2 (Moderate) & $06(15.79 \%)$ \\
3 (High) & $15(39.47 \%)$ \\
4 (Severe) & $17(44.74 \%)$ \\
& \\
\hline Urinary ketone bodies & \\
Trace $(5 \mathrm{mg})$ & $00(0.00 \%)$ \\
Small $(15 \mathrm{mg})$ & $00(0.00 \%)$ \\
Medium $(40 \mathrm{mg})$ & $18(47.37 \%)$ \\
Large( $>80 \mathrm{mg})$ & $20(52.63 \%)$ \\
\hline Severity of DKA based on VBG & \\
Mild & $13(34.21 \%)$ \\
Moderate & $17(44.73 \%)$ \\
Severe & $08(21.06 \%)$ \\
\hline
\end{tabular}

of up to two years followed by $26.66 \%(\mathrm{n}=8)$, $23.33 \%(\mathrm{n}=7)$ and $6.66 \%(\mathrm{n}=2)$ patients with the diabetic history of two to four years, four to six years and six to eight years respectively. Forty-five percent of patients had moderate DKA $(\mathrm{n}=17)$ followed by $34.21 \%(n=13)$ with mild DKA and $21.05 \%(\mathrm{n}=8)$ with severe DKA.

Leucocytosis was observed in $73.68 \%$ patients $(\mathrm{n}=$ 28). Hyponatremia and hypokalaemia were seen in $78.95 \%(\mathrm{n}=30)$ and $65.79 \%(\mathrm{n}=25)$ patients respectively. Table 3 represents the other laboratory profiles of DKA patients. The average duration of stay in hospital was $8.23 \pm 5.2$ days. There was no mortality in DKA patients.

\section{DISCUSSION}

DKA is a result of deficiency of circulating insulin and increased levels of the counter-regulatory hormones (glucagon, growth hormone, catecholamines and cortisol). The combination of lack of relative or absolute insulin and high concentration of counter-regulatory hormones cause an elevated catabolic state accompanied by increased glucose secretion by the kidney and liver via gluconeogenesis and glycogenolysis and also 
impaired peripheral glucose usage, resulting in hyperosmolality and hyperglycaemia. ${ }^{11}$

In this study, 38 children below the age of 18 years were studied and the mean age of the patients was $7.4 \pm 3.7$ years with male:female ratio of $0.9: 1$. This is similar to the previous study conducted by Al-Eisa A et al. ${ }^{12}$ Osmotic symptoms including polyuria, polydipsia, polyphagia, vomiting and fatigue are usually observed in initial stages of DKA. With the progression of acidosis, the pattern of breathing become more fast, deep and agonal, called Kussmaul breathing. ${ }^{13}$ The commonest clinical presentation along with dehydration reported in our study were Kussmaul breathing, vomiting, fever, polyuria and altered sensorium. Other studies conducted in other parts of India also showed vomiting, polyuria and polydipsia as the commonest symptoms. ${ }^{14}$ DKA is characterised by severe depletion of water and electrolytes from both intra and extracellular fluid compartments. ${ }^{15}$ We observed dehydration in all the patients of which mild, moderate and severe dehydration was present in $44.74 \%, 39.47 \%$ and $15.79 \%$ respectively. While hyponatremia and hypokalaemia were seen in $78.95 \%(n=30)$ and $65.79 \%(n=25)$ patients respectively. Ahmed S et al also reported dehydration in all the patients. However, other most common clinical presentations in their study included polyuria, respiratory distress, polydipsia. ${ }^{16}$ This mild variation in the symptoms in different studies can be directly attributed to the severity of the cases and awareness among the individuals.

Management of T1DM includes monitoring of blood glucose levels and life-long insulin therapy. However, poor compliance due to inadvertent omission with insulin therapy among 50\% patients in established T1DM can solely be attributed to either financial constrain or lack of education and parental knowledge. There was not a single patient who omitted insulin deliberately as a psychological cause or due to limited access to medical services. In the study conducted by Del Pozo P et al., poor compliance was observed in $66.6 \%$ patients. $^{2}$ Insulin omission can be prevented by comprehensive programs that provide education, psychosocial evaluation and treatment combined with adult supervision of the entire process of insulin administration. ${ }^{17}$ The infections, febrile illnesses, trauma change the body's metabolism and homeostasis resulting in drop in insulin level and increased glucagon and adrenaline levels. The liver also tends to release more glucose ensuring that sufficient energy is available. Concurrently, growth hormone and cortisol levels rise, reducing the sensitivity of tissues towards insulin and increasing glucose level. ${ }^{18}$ This triggers episodes of DKA. We observed UTI as the commonest trigger. Several studies in the past also have reported infections as the commonest precipitants. ${ }^{19,20}$

Certain viruses like Coxsackie virus B, CMV, adenovirus, mumps, rubella have been reported to target exocrine pancreas and are known to be associated with T1DM. ${ }^{21,22}$ This is reflected in this study too as $36.8 \%$ had the history of viral fever. However, the mechanism behind development of autoantibodies due to viremia is not clear. We also noted significantly high number of patients (94\%) being diagnosed in the winter. This was also reported Baruah MP et al. who attributed this to sudden environmental changes and the pattern of eating. ${ }^{23}$

In our study, $29 \%$ had parental history of diabetes. The risk of developing diabetes increases if both the parents are diabetic. ${ }^{24}$ Paternal diabetes is found to show a stronger association with diabetes in the offspring than maternal. This is also reflected in this study where $26.3 \%$ of patients gave a history of paternal diabetes while only $2.6 \%$ patients gave a history of maternal diabetes. The association of certain combination of HLA with significantly higher risk of developing T1DM have been reported, especially the combinations of HLADQA1, HLA-DQB1, and HLA-DRB1 gene variations. This combination of HLA genes seems to escalate the risk of beta cell destruction. ${ }^{25}$

High birth weight and rapid weight gain in initial years of life are associated with risk of T1DM. ${ }^{26,27}$ We also found a weak association between birth weight and the risk of diabetes as $76 \%$ T1DM children had normal birth weight. Stene LC et al. had also reported similar findings. ${ }^{28}$ Effect of birth order on risk of T1DM is still a topic of debate. The finding of this study reflects that the children born later are less prone to T1DM but further research in this arena is required. Breast milk is thought to be the best suited diet during the 
initial days of life due to the presence of immunoglobulins. The majority of the patients in this study were exclusively breast milk fed which reflects that onset of T1DM was due to other factors.

Growth is usually influenced by duration of diabetes, metabolic control, genetic endowment, puberty, and growth hormone level including IGF binding proteins (IGFBPs) and insulin-like growth factors (IGFs). ${ }^{29} \mathrm{We}$ also noticed that $75 \%$ and $52 \%$ children were below $3^{\text {rd }}$ percentile for height and weight respectively.

VBG analysis in this study revealed that $21.06 \%$ patients had severe DKA, $44.73 \%$ moderate and $34.21 \%$ mild level of DKA respectively. Kanwal SK et al. reported severe DKA in $61.8 \%$ patients. ${ }^{14}$ This variation may have been attributed to different population groups.
This study attempts to elaborate on the clinical profile of DKA in children. Although it is single centric, small study, it is hoped that this study would provide insight into the clinical profile of DKA children and stimulate further multi-centric, larger study in the future.

\section{CONCLUSIONS}

DKA can be diagnosed early by identifying certain clinical features like dehydration, Kussmaul breathing, vomiting, fever, polyurea and altered sensorium. Infection and poor compliance due to omission of insulin therapy were the commonest precipitating factors for DKA in Indian children.

\section{REFERENCES}

1. Krzewska A, Ben-Skowronek I. Effect of associated autoimmune diseases on type 1 diabetes mellitus incidence and metabolic control in children and adolescents. BioMed Res Int. 2016;1-12. DOI-https://doi.org/ $10.1155 / 2016 / 6219730$

2. Del Pozo P, Aránguiz D, Córdova GS, Valle P, Cerda J, García H, et al. Clinical profile of children with diabetic ketoacidosis in fifteen years of management in a Critical Care Unit. Rev Chil Pediatr. 2018 Aug;89(4):491-8. DOI-10.4067/S0370-41062018005000703

3. Cohen M, Shilo S, Zuckerman-Levin N, Shehadeh N. Diabetic ketoacidosis in the pediatric population with type 1 diabetes. Major topics of type 1 Diabetes. 2015 Nov 14;1:95-119. DOI-10.5772/60592

4. Wolfsdorf JI, Glaser N, Agus M, Fritsch, Hanas R, Rewers A, et al. ISPAD Clinical Practice Consensus Guidelines 2018: Diabetic ketoacidosis and the hyperglycemichyperosmolar state. Pediatr Diabetes. 2018;19(27):155-77. DOI-10.1111/pedi.12701

5. Murunga AN, Owira PM. Diabetic ketoacidosis: an overlooked child killer in sub Saharan Africa? Trop Med Int Health. 2013;18:1357-64. DOI-10.1111/tmi.12195

6. World Health Organisation. Global report on diabetes. 2016.

7. Muktan D, Ghising LT, Singh RR. Clinical Profile of Diabetic Ketoacidosis among Children in Eastern Nepal. JCMSN. 2019;15(4); 226-9. DOI- https://doi.org/10.3126/jcmsn.v15i4.21985

8. Bairwa M, Rajput M, Sachdeva S. Modified Kuppuswamy's socioeconomic scale: Social Researchers should include updated income criteria. Ind J Com Med. 2013;38(3):185-6. DOI-10.4103/0970-0218.116358

9. WHO Multicentre Growth Reference Study group. WHO child growth Standards: Length/height for age, weight for age, weight for length, weight for height and body mass index for age: Methods and development. Geneva, Switzerland: World Health Organization, 2006.

10. Khadilkar V, Yadav S, Agrawal KK, Tamboli S, Banerjee M, Cherian A, et al. Revised IAP Growth Charts for Height, Weight and Body mass Index for 5 to 18 year old Indian Children. Indian Pediatr. 2015; 52:47-55. DOI-10.4103/2230-8210.159028

11. Raghupathy P. Diabetic ketoacidosis in children and adolescents. Indian J Endocr Metab. 2015 Apr;19(1):55-7. DOI-10.4103/2230-8210.155403

12. Al-Eisa AA, Al-Hajri A, Al-Shuaib S, Razzak DM, Al-Basiri I. Early-onset microalbuminuria in children with type 1 diabetes in Kuwait. Current Pediatr Res. 2017;21(2): 254-9. 
13. de Moraes AG, Surani S. Effects of diabetic ketoacidosis in the respiratory system. World J Diabetes. 2019;10(1): 16-22. DOI-https://dx.doi.org/10.4239/wjd.v10.il.16.

14. Kanwal SK, Bando A, Kumar V. Clinical profile of diabetic ketoacidosis in Indian children. Indian J Pediatr. 2012;79(7):901-4. DOI-https://doi.org/10.1007/s12098-011-0634-3.

15. Palmer BF, Clegg DJ. Electrolyte and acid base disturbance in patients with diabetes mellitus. N Engl J Med. 2015;373(6):548-59. DOI-10.1056/NEJMra1503102

16. Ahmed S, Jan M, Rashid I, Rashid T, Shahzad N. Clinical Profile and Outcome of Pediatric Patients with Diabetic Ketoacidosis. IOSR-JDMS. 2015;14(3):22-6. DOI- 10.9790/0853-14332226

17. Golden MP, Herrold AJ, Orr DP. An approach to prevention of recurrent diabetic ketoacidosis in the paediatric population. J Pediatr. 1985;107(2):195-200. DOI-10.1016/s0022-3476(85)80124-4.

18. Dose CI. Diabetes Education Online, Diabetes Teaching Center at the University of California, San Francisco. 2017.

19. Seth P, Kaur H, Kaur M. Clinical profile of diabetic ketoacidosis: a prospective study in a tertiary care hospital. J Clin Diagn Res. 2015;9(6):01-4. DOI-10.7860/JCDR/2015/8586.5995

20. Umpierrez GE, Murphy MB, Kitabchi AE. Diabetic ketoacidosis and hyperglycemic hyperosmolar syndrome. Diabetes Spectr. 2002;15(1):28-36. DOI- https://doi.org/10.2337/diaspect.15.1.28

21. Ramondetti F, Sacco S, Comelli M, Bruno G, Falorni A, Iannilli A, et al. Type 1 diabetes and measles, mumps and rubella childhood infections within the Italian Insulin-dependent Diabetes Registry. Diabet Med. 2012;29(6):761-6. DOI-10.1111/j.1464-5491.2011.03529.x

22. Jaidane H, Hober D. Role of coxsackievirus B4 in the pathogenesis of type 1 diabetes. Diabetes Metab. 2008;34(6): 537-48.DOI: 10.1016/j.diabet.2008.05.008

23. Baruah MP, Ammini AC, Khurana ML. Demographic, breast-feeding, and nutritional trends among children with type 1 diabetes mellitus. Indian J Endocrinol Metab. 2011;15(1):38-42. DOI-10.4103/2230-8210.77583

24. Parkkola A, Härkönen T, Ryhänen SJ, Ilonen J, Knip M. Finnish Pediatric Diabetes Register. Extended family history of type 1 diabetes and phenotype and genotype of newly diagnosed children. Diabetes Care. 2013;36(2): 348-54. DOI: https://doi.org/10.2337/dc12-0445

25. National Library of Medicine. Genetics home reference: your guide to understanding genetic conditions

26. Ferdi NE, Khalida AB, Chenchouni $\mathrm{H}$. Effect of socioeconomic factors and family history on the incidence of diabetes in an adult diabetic population from Algeria. Iran J Public Health. 2016;45(12):1636-44. PMID 28053930

27. Rewers M, Ludvigsson J. Environmental risk factors for type 1 diabetes. The Lancet. 2016;387(10035):2340-2348. DOI-10.1016/S0140-6736(16)30507-4

28. Stene LC, Magnus P, Lie RT, Søvik O, Joner G. Norwegian Childhood Diabetes Study Group. Birth weight and childhood onset type 1 diabetes: population based cohort study. BMJ. 2001;322(7291):889-92. DOI: 10.1136/bmj. 322.7291 .889

29. Virmani A. Growth disorders in type 1 diabetes: an Indian experience. Ind J Endocrinol Metab. 2015;19(1): 64-7.DOI-10.4103/2230-8210.155405 